\title{
Co-combustion of biodiesel with oxygenated fuels in direct injection diesel engine
}

\author{
Wojciech Tutak ${ }^{1, *}$, Arkadiusz Jamrozik ${ }^{1}$ and Michat Pyrc $^{1}$ \\ ${ }^{1}$ Czestochowa University of Technology, Faculty of Mechanical Engineering and Computer Science, \\ 42-201 Czestochowa, Armii Krajowej 21 Av., Poland
}

\begin{abstract}
The paper presents results of experimental investigation of cocombustion process of biodiesel (B100) blended with oxygenated fuels with $20 \%$ in volume. As the alternative fuels ware used hydrated ethanol, methanol, 1-butanol and 2-propanol. It was investigated the influence of used blends on operating parameters of the test engine and exhaust emission $\left(\mathrm{NO}_{\mathrm{x}}, \mathrm{CO}, \mathrm{THC}, \mathrm{CO}_{2}\right)$. It is observed that used blends are characterized by different impact on engine output power and its efficiency. Using biodiesel/alcohol blend it is possible to improve engine efficiency with small drop in indicated mean effective pressure (IMEP). Due to combustion characteristic of biodiesel/alcohol obtained a slightly larger specific $\mathrm{NO}_{\mathrm{x}}$ emission. It was also observed some differences in combustion phases due to various values of latent heat of evaporation of used alcohols and various oxygen contents. Test results confirmed that the combustion process occurring in the diesel engine powered by blend takes place in a shorter time than in the typical diesel engine.
\end{abstract}

\section{Introduction}

Co-combustion of fuel blends is one of the methods to utilize alternative fuels in internal combustion engines. Renewable biofuels are important energy resources for reduction of green house gases, better air quality, less dependency on oil imports, and new jobs and markets [1]. Reducing emissions of toxic compounds is the subject of many activities both engineers and legislators [2]. Co-combustion of fuels is used not only in relation to liquid or gas fuels and it is used for solid fuels as well $[3,4]$. The use of biodiesel or its blends with diesel has a negative impact on cold operation of engine under $0^{\circ} \mathrm{C}$ and increases $\mathrm{NO}_{\mathrm{x}}$ emissions as compared to diesel. In the first solutions of co-combustion in diesel engines gas fuel was used [5]. The gas was delivered into the engine intake system through the mixer. In order to reduce nitrogen oxides emissions especially in industrial gas engines used the twostage combustion systems $[6,7,8]$. As an alternative fuel for compression ignition engines the so-called oxygenated fuels are used. Alcohol is a renewable fuel because it can be produced from the biomass [9]. These fuels in the structure have oxygen, which affects the combustion process. Moreover, alcohols have several important disadvantages such as low cetane numbers and high latent heat of evaporations, and cannot be directly used in diesel

\footnotetext{
*Corresponding author: tutak@imc.pcz.czest.pl
} 
engines $[1,10,11]$. In recent years, to power diesel engines the mixtures of diesel or biodiesel with alcohols were used. Alcohols causes phase separation at low temperature. Fraction of alcohol in blend cannot be high due to low value of cetane number of alcohol which causes the increase in ignition delay. As the number of carbon in alcohols increases, they can be more easily blended with diesel and biodiesel. With the increase of carbon in alcohols, the mass percent of oxygen decreases while cetane number, density and calorific value increase $[12,13]$. Moreover, because these higher alcohols have good solvent capabilities, they can easily be blended with diesel and biodiesel $[12,13]$. The alternative fuels are derived from animal fats or in the cultivation process of algae $[14,15]$. In practice the combustion process of more than one fuel is possible by using dual fuel technology or blend mode. In dual fuel technology are used two independent power supply systems, one is an existing direct injection system which delivers diesel fuel and second is so called fumigation system which injects an alcohol fuel into the intake port of an internal combustion engine. Into the engine cylinder the air-fuel mixture, nearly homogeneous is delivered. The ignition process is controlled by the injected dose of diesel fuel. This requires addition of an injector, along with a separate fuel tank, lines and controls [10]. The second method is to provide fuels blend to engine combustion chamber by direct injection system. This system is a simpler solution because it does not require practically any changes in the engine construction. Blend of fuels diesel/alcohol is prepared and then bring the mixture to the engine, using a typical supply system for a diesel engine [11]. The biggest difficulty is that the large percentage of alcohol do not mix with diesel fuel, hence use of diesel-alcohol blends is not feasible. Also, the blends are not stable and separate in the presence of trace amounts of water. In such a power system cannot change the ratio of diesel/alcohol [11]. In the literature is lot of works on diesel-biodiesel-alcohol or diesel-esters mixtures co-combustion in diesel engine [14]. As the oxygenated fuels is considered ethanol which can be produced by the fermentation of natural sugars, starches or cellulosic biomass. In paper [16] authors presented results of experimental investigation of co-combustion of hydrated ethanol blend with diesel fuel in direct injection diesel engine. They stated that with increase in ethanol fraction in blend increased the ignition delay and decreased combustion duration as well. In addition they stated that with increase in ethanol fraction increased $\mathrm{NO}_{\mathrm{x}}$ emission with near to constant THC emission and increased unrepeatability of IMEP. Other alcohol taken into account as an alternative fuel is methanol. Methanol is also known as wood alcohol. Presently, methanol is produced from synthetic gas or biogas and is used as a fuel for IC engines [17]. In paper [18] are presented results of combustion analysis of methanol/diesel blends based on the cylinder pressure analysis in a compression-ignition engine. The results showed that increasing methanol mass fraction in the methanol/diesel blends resulted in the increase of the heat release rate in the premixed burning phase and shortening of the combustion duration of the diffusive burning phase [18]. The results indicated that by using methanol-blended diesel fuels, smoke opacity, CO and THC emissions reduced while $\mathrm{CO}_{2}$ and $\mathrm{NO}_{\mathrm{x}}$ emissions increased. Propanol is a 3-carbon structure, straight chain alcohol with higher energy density and higher cetane number which makes it a potential alternative to lighter alcohols (methanol and ethanol) as blending component with diesel [19]. In the paper [20] authors presented results of the impact of propanol as additive to diesel fuel on engine performance. Propanol reduced the smoke emissions of rapeseed oil but increased $\mathrm{NO}_{\mathrm{x}}$, total hydrocarbons (THC) and $\mathrm{CO}$ emissions significantly. A drop in peak pressure and a slight increase in ignition delay were observed with increasing propanol content in the oil [20]. Propanol fraction in blend causes improvement in performance of the engine due to the higher percentage of premixed combustion as a result of low cetane number of propanol. Butanol is one of the alcohols which have more advantages than ethanol and methanol as an alternative fuel for internal combustion engines. This alcohol has properties closer to fossil-based fuels. Butanol has a lower auto-ignition temperature than methanol and ethanol. Therefore, butanol can be ignited 
easier when burned in diesel engines. Author of paper [21] presented results of experimentally investigation of the performance, combustion characteristics, NO emissions, and stability of a diesel engine fuelled by diesel - biodiesel - butanol blend. They stated that the addition of butanol with a percentage of up to $20 \%$ to the biodiesel - diesel fuel blend resulted in a tolerable change in the engine performance, combustion characteristics, NO emission, and engine stability compared to the diesel fuel, which indicates that the butanol has a great potential to be used as a fuel additive in the diesel engines [21].

In this paper are presented results of comparative analysis of diesel engine powered by four blends of biodiesel with four alcohols: ethanol, methanol, 2-propanol and 1-butanol. Composition of blend consists of $80 \%$ biodiesel and $20 \%$ alcohol in volume fraction. There is presented an analysis of thermodynamic parameters and emission characteristics of engine powered by blends for the same engine settings.

\section{Experimental setup}

The study was conducted on the 1-cylinder direct injection natural aspired diesel engine. Detailed engine parameters are presented in Table 1. Tests conducted with a constant angle of diesel fuel injection and constant rotational speed equal to $1500 \mathrm{rpm}$. The test stand was equipped with measurement system (Fig. 1). At each mode of operation, the engine was allowed to run 5 minutes until the exhaust gas temperature and exhaust gas composition have attended steady-state values and data acquisition process was subsequently conducted. The ambient temperature was maintained at a constant level. Each experiment was conducted three times and the results were found to agree with each other with the $95 \%$ significance level.

Table 1. Main engine parameters.

\begin{tabular}{|c|c|c|}
\hline Parameter & Value & unit \\
\hline Displacement volume & 0.573 & $\mathrm{dm}^{3}$ \\
\hline Bore & 90 & $\mathrm{~mm}$ \\
\hline Stroke & 90 & $\mathrm{~mm}$ \\
\hline Compression ratio & $17: 1$ & - \\
\hline Rated power (at 3000 rpm) & 7 & $\mathrm{~kW}$ \\
\hline Crankshaft rotational speed & 1500 & $\mathrm{rpm}$ \\
\hline Injection pressure & 210 & bar \\
\hline Injection timing & 17 & deg bTDC \\
\hline
\end{tabular}

Measuring system:

- Exhaust gas analyzer: THC, $\mathrm{CO}, \mathrm{CO}_{2}, \mathrm{O}_{2}-$ Bosch BEA 350: THC: range 0 - 9999 ppm vol, accuracy: $12 \mathrm{ppm}$ vol, $\mathrm{CO}$ : range $0-10 \%$ vol, accuracy: $0.06 \%$ vol, $\mathrm{CO}_{2}$ : range 0 $-18 \%$ vol, accuracy: $0.4 \%$ vol, $\mathrm{O}_{2}$ : range $0-22 \%$ vol, accuracy: $0.1 \%$ vol, : range 0.5 - 9.999, accuracy: 0.01,

- Exhaust gas analyzer: $\mathrm{NO}_{\mathrm{x}}$ - Radiotechnika AI9600: accuracy: 32 ppm for range 0 1000 ppm,

- In-cylinder pressure sensor - Kistler 6001, sensitivity: $\pm 0.5 \%$,

- Charge amplifiers - Kistler 5001, linearity of FS $< \pm 0,05 \%$,

- Air/Fuel Ratio Meter LM-2, range 7.35-22.38,

- Data acquisition module - National Instruments USB-6251 - 16 bits resolution, sampling frequency $20 \mathrm{kHz}$, Resolution for the data acquisition system - 1.0 CA deg, with software [22]. 


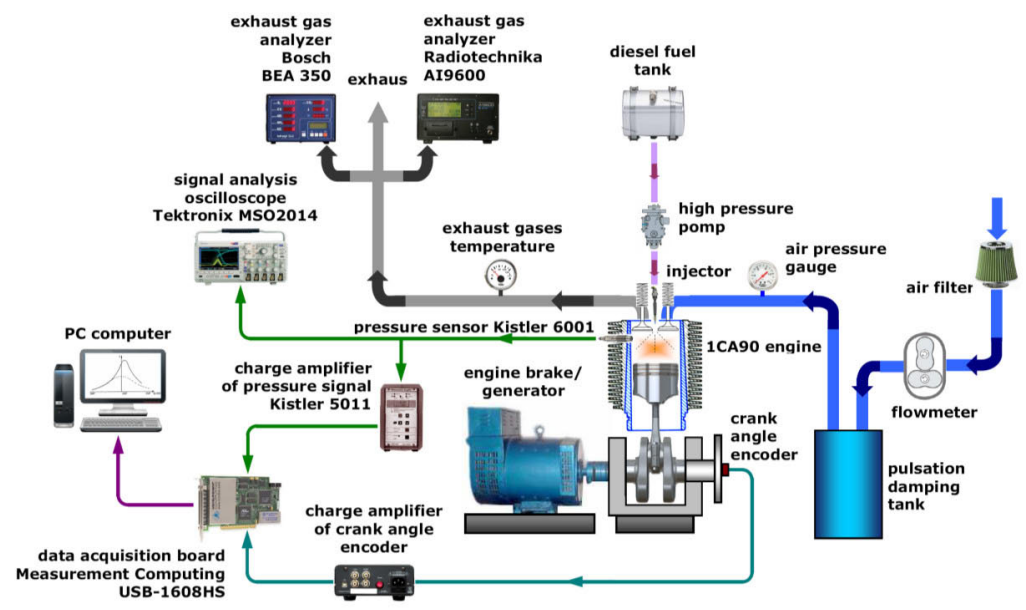

Fig. 1. The test stand.

The motivation of this study was to compare operating parameters and emission characteristics of compression ignition engine powered by blends: biodiesel-ethanol (BE), biodiesel-methanol (BM), biodiesel-propanol (BP) and biodiesel-butanol (BB). The used blends consist of $80 \%$ biodiesel (B100) and $20 \%$ alcohol in volume. The researches ware conducted under the same conditions, with unchanged settings of the test engine. With such a power system is guaranteed the same volumetric dosage of injected fuel. For all analyzed cases recorded 100 consecutive engine cycles. Each measurement was carried out three times. Parameters of engine obtained by biodiesel supply were taken as a reference for blends. In Table 2 fuels properties are presented. In Table 3 the main parameters of blends are presented.

Table 2. Fuels properties.

\begin{tabular}{|c|c|c|c|c|c|}
\hline \multirow{2}{*}{ Formula } & $\begin{array}{c}\mathrm{B} 100 \\
(\mathrm{~B})\end{array}$ & $\begin{array}{c}\text { Methanol } \\
(\mathrm{M})\end{array}$ & $\begin{array}{c}\text { Ethanol } \\
(\mathrm{E})\end{array}$ & $\begin{array}{c}\text { Propanol } \\
(\mathrm{P})\end{array}$ & $\begin{array}{c}\text { Butanol } \\
(\mathrm{B})\end{array}$ \\
\cline { 2 - 6 } & $\mathrm{CH}_{3}\left(\mathrm{CH}_{2}\right) \mathrm{nCOOH}_{3}$ & $\mathrm{CH}_{3} \mathrm{OH}$ & $\mathrm{C}_{2} \mathrm{H}_{5} \mathrm{OH}$ & $\mathrm{C}_{3} \mathrm{H}_{7} \mathrm{OH}$ & $\mathrm{C}_{4} \mathrm{H}_{9} \mathrm{OH}$ \\
\hline Cetane number & 56 & 2 & 11 & 12.0 & 15 \\
\hline LHV, MJ/kg & 37 & 20 & 26.8 & 30.6 & 33.8 \\
\hline Latent heat of evaporation, kJ/kg & 300 & 1162 & 918 & 727.9 & 626 \\
\hline Carbon (by wt. \%) & 77.1 & 37.48 & 52.14 & 60.0 & 64.82 \\
\hline Hydrogen (by wt. \%) & 12.1 & 12.48 & 13.02 & 13.3 & 13.49 \\
\hline Oxygen (by wt. \%) & 10.8 & 49.93 & 34.73 & 26.6 & 21.59 \\
\hline Density, kg/m ${ }^{3}$ & 832 & 791 & 789 & 815.0 & 810 \\
\hline Auto-ignition temperature, $\mathrm{K}$ & 534 & 658 & 698 & 573.0 & 616 \\
\hline
\end{tabular}

It is visible that alcohols are characterized by lower LHV and cetane number in comparison with biodiesel but higher value of heat of evaporation (Fig. 2). With the increase in carbon atoms in alcohol particle increases LHV and cetane number which makes them more acceptable to the engine. Viscosity and density are two crucial properties for engine performance because it affects spray formation, spray penetration, fuel droplet size, injection timing, injection pressure, atomization and combustion characteristics [10]. Propanol is a 3carbon and butanol 4-carbon structure with higher energy density and higher cetane number which makes these alcohols a potential alternative to lighter alcohols such as methanol and ethanol. Butanol is characterized by relatively high value of cetane number which is better than lower alcohols to help auto ignition. 
Table 3. Blends properties.

\begin{tabular}{|c|c|c|c|c|c|}
\hline & B100 & BM20 & BE20 & BP20 & BB20 \\
\hline LHV, MJ/kg & 37 & 33.6 & 34.96 & 35.72 & 36.36 \\
\hline $\begin{array}{c}\text { Latent heat of evaporation, } \\
\mathrm{kJ} / \mathrm{kg}\end{array}$ & 300 & 472.4 & 423.6 & 385.57 & 365.2 \\
\hline Oxygen content, \% wt. & 10.8 & 18.6 & 15.6 & 13.9 & 12.9 \\
\hline
\end{tabular}

In Fig. 2 is the comparison of fuels composition. It can be indicated that hydrogen content in fuels is near the same. In alcohols with the increase in carbon in structure the oxygen atoms decreased. In case of methanol the oxygen content is near to $50 \%$ in mass. Biodiesel is characterized by the lowest oxygen content from all analyzed fuels. In case of blends the biodiesel - methanol blend has the highest oxygen content.

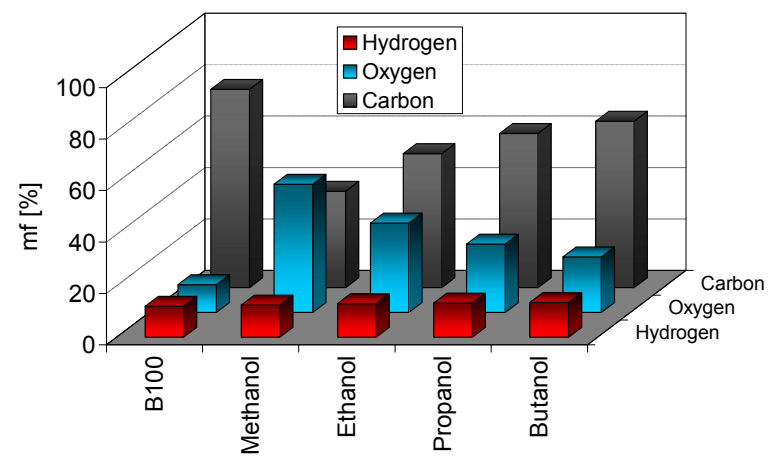

Fig. 2. Fuels mass fraction.

In Fig. 3 the comparison of LHV and heat of evaporation of sole fuels and blends is presented. The higher value of LHV has B100 and in case of blends the BB20 has the highest value of LHV.
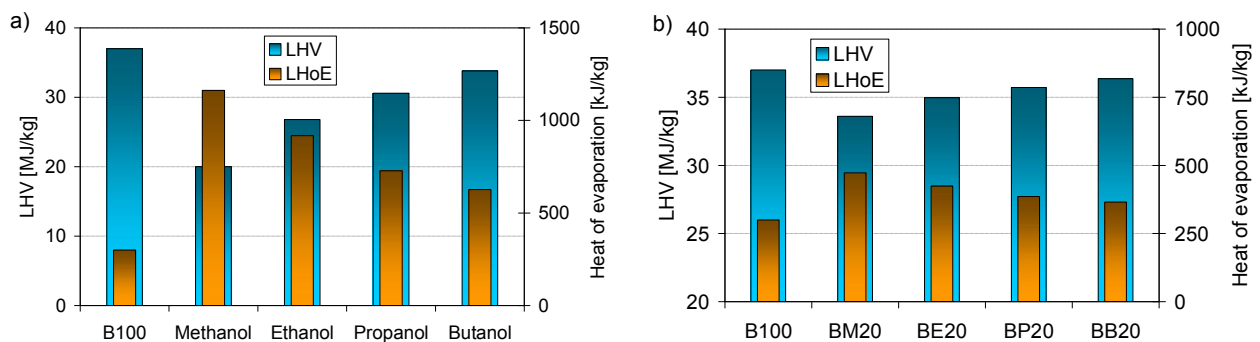

Fig. 3. Comparison LHV of fuels (a) and blends (b) used during investigation.

The dominant component in the blend is biodiesel B100 and its properties largely determine the properties of the mixture. Nevertheless, the addition of alcohol causes a change in the value of both LHV and heat of evaporation of the blend (Fig. 3b). It is visible that with the increase in carbon atoms in the structure of alcohol the LHV of blend increased as well. LHV of blends are lover than for B100. 


\section{Results and discussion}

During experimental researches obtained the in-cylinder pressure traces vs. crank angle and emission of exhaust gases. On the basis of indication results thermodynamic parameters of the test engine such as: indicated mean effective pressure (IMEP), indicated thermal efficiency (ITE), specific fuel consumption (SFC), heat release and combustion phases were determined.

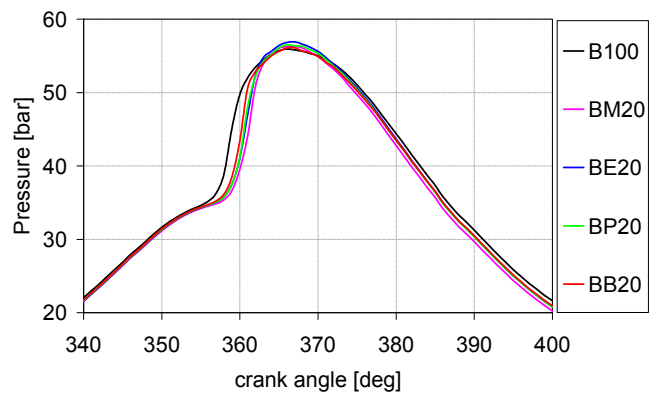

Fig. 4. In-cylinder pressure traces.

In Fig. 4 the pressure traces for engine powered by biodiesel and blends are presented. It can be stated that with alcohol participation in fuel the combustion process occurs with delay in comparison to B100. There are no significant differences in the peak pressure. Generally with increase in ignition delay during combustion process in diesel engine it is obtained higher value of peak pressure. In this case due to lower value of LHV of alcohol does not notice that increase in peak pressure.
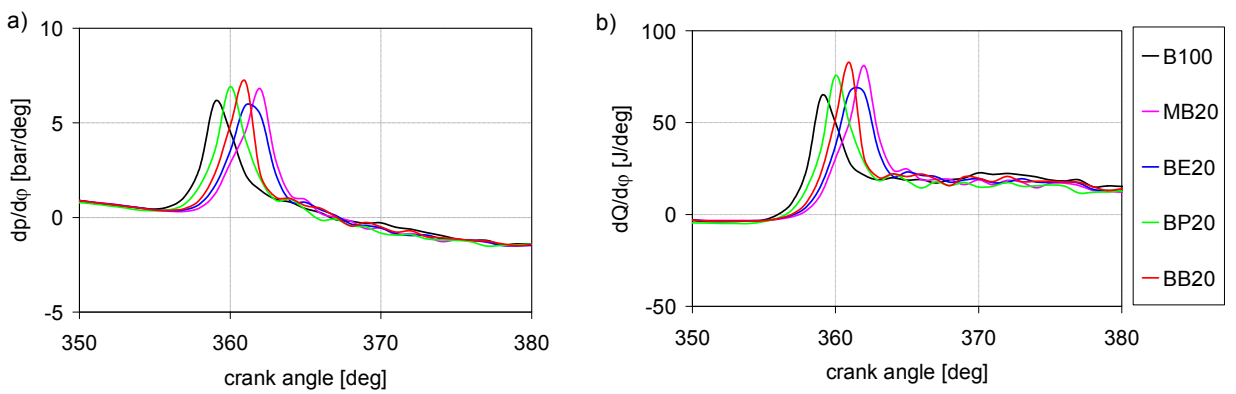

Fig. 5. The pressure rise and heat release rate.

In Fig. 5 courses of pressure rise and heat release rate for analyzed cases are presented. The peak pressure rises provide information about hardness of the engine. In all analyzed cases the maximum of $\mathrm{dp} / \mathrm{d} \varphi$ was less than $10 \mathrm{bar} / \mathrm{deg}$ which is the limit value for a diesel engine. The higher value of $\mathrm{dp} / \mathrm{d} \varphi$ reached for biodiesel-butanol blend and it was equal to $7.2 \mathrm{bar} / \mathrm{deg}$ and it was higher of $15 \%$ compared to B 100 powering. It can be explained by the fact that butanol is characterized by relatively high LHV and the lowest value of the heat of vaporization of used alcohols. On the basis of pressure traces the heat release rate traces which are used to describe combustion process were calculated. On the basis of heat release rate courses can be stated that alcohol fraction in blend causes ignition delay and heat release occurs more rapidly. For all blends combustion received higher values of $d Q / d \varphi$ compared to B100 fuelling. Near the same values of maximum dQ/d $\varphi$ obtained for BB20 and BM20 blends but for BM20 it was obtained for larger angles after TDC. It was due to higher value of heat of evaporation of methanol which causes increase in ignition delay and burning after 
ignition occurs very rapidly. In case of biodiesel-ethanol fuelling of engine the $d Q / d \varphi$ course has a slightly different shape. Combustion process of BE blend occurred with lowest rate from blends and it was the most extended in time. It can be explained among other things, the water content in ethanol which had an impact on the combustion process. Longer ignition delays as a result of lower cetane number of alcohols causes a wider fraction of the fuel to burn during the premixed combustion phase. The enhanced oxygen content of alcohol improves the combustion process, particularly during the diffusion phase [19].
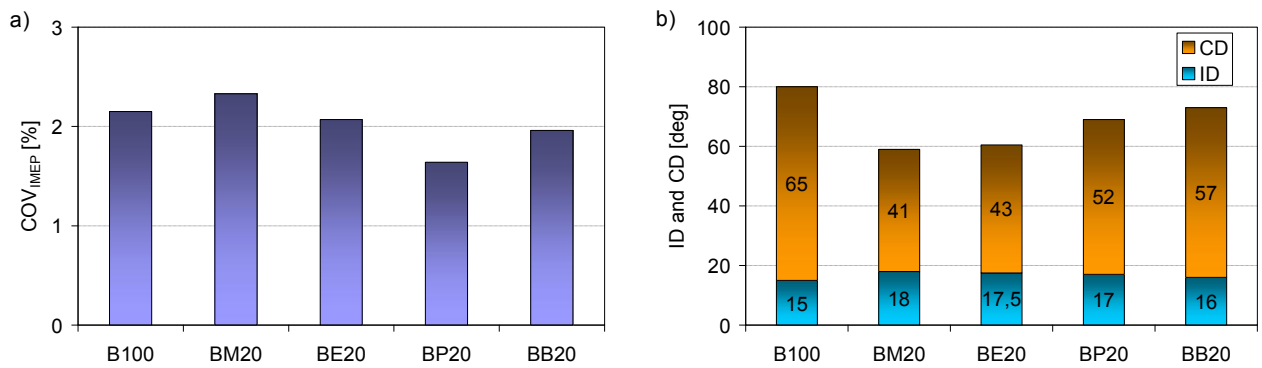

Fig. 6. Unrepeatability of IMEP (a) and combustion phases (b).

In Fig. 6a the coefficient of unrepeatability of IMEP ( $\left.\mathrm{COV}_{\text {IMEP }}\right)$ for all analyzed cases is presented. It is assumed that the engine unrepeatability of IMEP should not exceed $10 \%$. On unrepeatability of engine cycles has the impact, among others, flow processes occurred during intake stroke [23]. In all analyzed cases $\mathrm{COV}_{\text {IMEP }}$ was at the level o $2 \%$. The lowest value of $\mathrm{COV}_{\text {IMEP }}$ reached at $\mathrm{BP} 20$ burn and it was equal to $1.65 \%$ and the highest value obtained at BM20 fuelling 2.35\%. In case of combustion phases the lowest value of ignition delay (ID) obtained for the engine powered by B100 and it was $15 \mathrm{deg}$ of CA, the highest value of ID reached for powering by BM20 and it was equal $18 \mathrm{deg}$ of CA. The participation of alcohol in the blend causes the increase in ignition delay. With the increase in carbon (C) content in the alcohol structure the impact on ID is getting smaller due to lower value of latent heat of evaporation and the rising cetane number (Tab. 1 and 2). Analyzing the combustion duration (CD) it can be stated that the presence of alcohol in blend with small carbon content in the structure (methanol and ethanol) causes a significant reduction in the CD. In case of BM20 the combustion duration was equal to 42 deg of CA but for BB20 (alcohol with 4-carbon in the structure) the $\mathrm{CD}$ was equal to $57 \mathrm{deg}$ of $\mathrm{CA}$ which was reduced by 8 deg relative to the $\mathrm{B} 100$ burning.
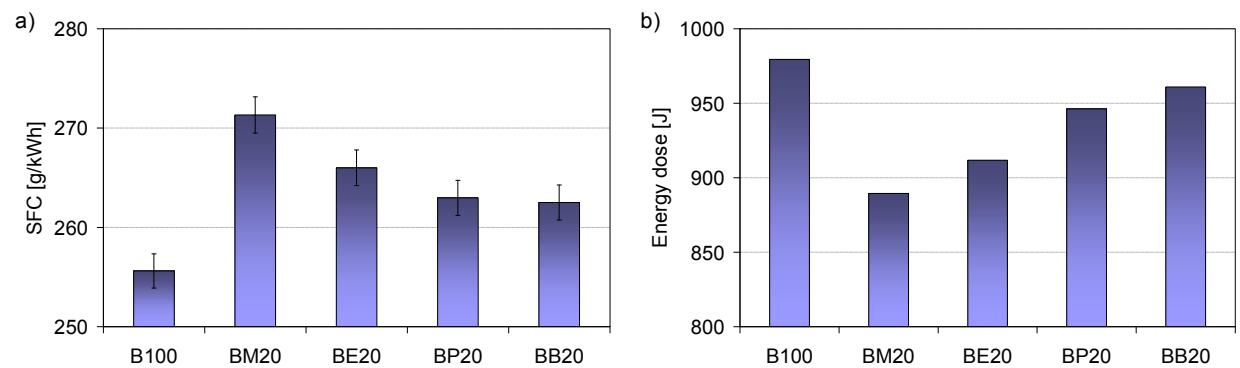

Fig. 7. Specific fuel consumption (a) and energy doses (b).

In Fig. 7 the specific fuel consumption and energy doses contained in fuel provided for engine cylinder for one engine cycle are presented. With the carbon mass fraction in alcohol the LHV increased as well (Table 1). Blend of B100 and methanol is characterized by the lowest LHV and therefore at a dose of fuel supplied to the cylinder is contained the smallest amount of energy. In BM blend in comparison with B100 it was a 10\% less energy. This was reflected 
in SFC which was the highest for BM powering and it was of $6 \%$ higher in comparison with B100 powering.
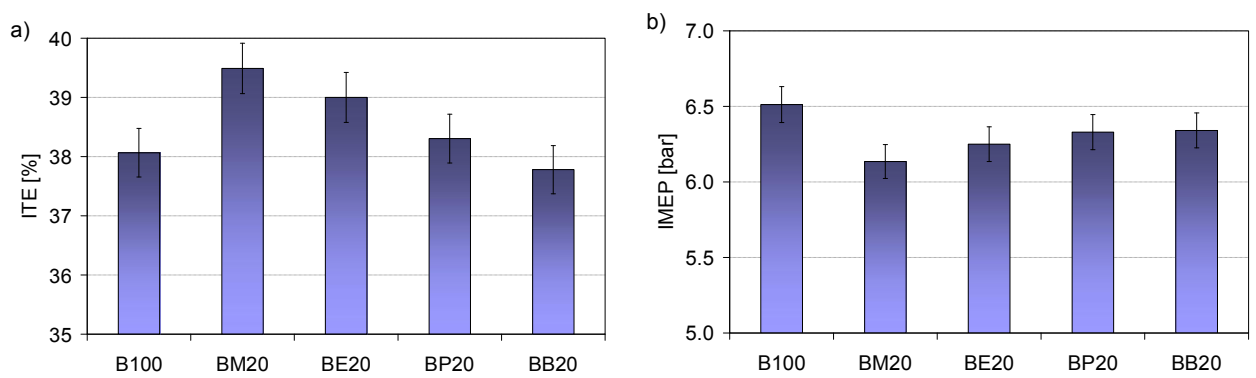

Fig. 8. Indicated thermal efficiency (a) and indicated mean effective pressure (b).

The heating value of alcohol increases with increase number of carbon atoms which indicates higher heating values for butanol from all analyzed alcohols. However, the heating value of butanol is 9.5\% lower than biodisel (B100) and hence would require more amount of biodiesel/butanol blends to produce the same power output in the engine. For the lower alcohols this ratio is even higher. Higher burning velocities of alcohols lead to higher efficiency [19]. The indicated mean effective pressure depends on energy dose supplied to the cylinder of engine (Fig. 7b). This relationship confirmed obtained results (Fig. 8b). For all blends obtained lower value of IMEP in comparison with B100 fuelling (Fig. 8a). In case of indicated thermal efficiency (ITE) the highest value obtained for BM20 burning and it was $1.5 \%$ higher than for B100. In case of BB20 burning the ITE reached lowest value.
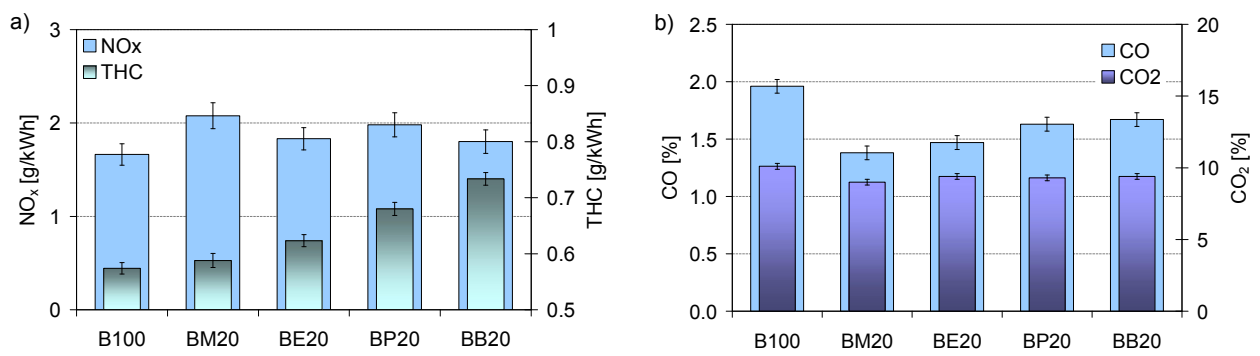

Fig. 9. Specific $\mathrm{NO}_{\mathrm{x}}$ and $\mathrm{THC}$ emission (a) and emission of $\mathrm{CO}$ and $\mathrm{CO}_{2}(\mathrm{~b})$.

In Fig. 9a the specific emissions of nitrogen oxides $\left(\mathrm{NO}_{\mathrm{x}}\right)$ and total unburned hydrocarbons (THC) are presented. The formation of $\mathrm{NO}_{\mathrm{x}}$ in the internal combustion engine is determined by the thermal mechanism, in which the most important parameters are the temperature of combustion and oxygen content [24]. In case of oxygenated fuels, such as alcohols, the oxygen content as well as the combustion temperature could be higher which leads to the higher $\mathrm{NO}_{\mathrm{x}}$ emissions. Co-combustion of biodiesel with oxygenated fuels increases the ignition delay of the mixture and the shortening of the combustion process which can also cause an increase in $\mathrm{NO}_{\mathrm{x}}$ emissions. On the other hand alcohols, compared to diesel and biodiesel, characterized by a lower calorific value and higher latent heat of evaporation which can lead to decrease of temperature in the cylinder and the reduction of $\mathrm{NO}_{\mathrm{x}}$. On the basis of the results it can be stated that THC emission increased with the presence of alcohol content in the blend. This is due to the higher latent heat of vaporization of alcohol which causes slow evaporation, incomplete air/fuel mixing and development of a quench layer. With the increase in carbon (C) content in the alcohol structure THC emission increased as well. In case of BB20 the specific THC emission was higher of $28 \%$ in comparison with B100 
fuelling. Analyzing the specific $\mathrm{NO}_{\mathrm{x}}$ emissions can be stated that presence of alcohol in the blend causes rather slight increase in $\mathrm{NO}_{\mathrm{x}}$ emission. The higher $\mathrm{NO}_{\mathrm{x}}$ emission was observed for the combustion of the BM20. It can be explained by the higher oxygen content in methanol which is almost $50 \%$ weight (Fig. 2). Emission of $\mathrm{CO}$ and $\mathrm{CO}_{2}$ generally are lower with alcohol content at full load of the engine due to the high in-cylinder temperature. In case of $\mathrm{CO}$ emission the lowest value obtained for BM20 burning and with the increase in carbon in the alcohol structure $\mathrm{CO}$ emission increased but does not exceed the value $(1.96 \%)$ obtained by B100 burning.

\section{Conclusions}

In the paper are presented experimental results of comparative analysis of co-combustion of oxygenated fuels with biodiesel in the direct injection diesel engine. The test engine was powered by blends of biodiesel with four alcohols: methanol, ethanol, 2-propanol and 1-butanol. Composition of blend consists of $80 \%$ biodiesel and $20 \%$ alcohol in volume. On the basis of indication results determined thermodynamic parameters of the test engine such as: indicated mean effective pressure (IMEP), indicated thermal efficiency (ITE), specific fuel consumption (SFC), heat release and combustion phases. Conclusions regarding the thermodynamic parameters of the test engine:

- there are no significant differences in the peak pressure,

- the higher value of $\mathrm{dp} / \mathrm{d} \varphi$ reached for biodiesel-butanol blend and it was equal to 7.2 $\mathrm{bar} / \mathrm{deg}$ and it was higher of $15 \%$ compared to B 100 powering,

- in all analyzed cases $\operatorname{COV}_{\text {IMEP }}$ was at the level of $2 \%$,

- the lowest value of ignition delay obtained for the engine powered by B100 and it was $15 \mathrm{deg}$ of CA, the highest value of ID reached for powering by BM20 and it was equal $18 \mathrm{deg}$ of $\mathrm{CA}$,

- the combustion duration (CD) in presence of alcohol in blend with small carbon content in the structure (methanol and ethanol) causes a significant reduction,

- in case of BM20 the CD was equal to $42 \mathrm{deg}$ of CA but for BB20 (alcohol with 4-carbon in the structure) the $\mathrm{CD}$ was equal to $57 \mathrm{deg}$ of $\mathrm{CA}$ which was reduced by 8 deg relative to the B100 burning

Conclusions regarding the exhaust emission of the test engine:

- THC emission increased with the presence of alcohol content in the blend,

- with the increase in carbon (C) content in the alcohol structure THC emission increased as well. In case of BB20 the specific THC emission was higher of $28 \%$ in comparison with B100 fuelling,

- the specific $\mathrm{NO}_{\mathrm{x}}$ emissions with presence of alcohol in the blend causes rather slight increase,

- $\mathrm{CO}$ and $\mathrm{CO}_{2}$ emissions generally are lower with alcohol content at full load of the engine due to the high in-cylinder temperature.

Presented study showed that it is possible to co-combustion of alcohols (as renewable biofuels) in compression ignition engine without decreasing its performance and to the benefit of the environment. At a constant volumetric dose of injected fuel and thus a smaller amount of energy in fuel dose it can be achieved an acceptable operating parameters of the engine. The next stage of investigation should be the optimization of the engine in terms of the fuel injection angle for all used blends. 
Acknowledgements: Research was also financed by the Ministry of Science and Higher Education of Poland from the funds dedicated to scientific research No. BS/PB 1-103-3030/2011/S.

\section{References}

1. A. Atmanli, Fuel 176, 6 (2016)

2. G. Szendr, A. Török, Transport 29, 5 (2014)

3. A. Kijo-Kleczkowska, K. Środa, M. Kosowska-Golachowska, T. Musiał, K. Wolski, Fuel 170, 19 (2016)

4. A. Kijo-Kleczkowska, K. Środa, M, Kosowska-Golachowska, T. Musiał, K. Wolski, Waste Manage. 53, 16 (2016)

5. W. Tutak, A. Jamrozik, Therm. Sci. 18, 1 (2014)

6. A. Jamrozik, W. Tutak, Chem. Process Eng. 32, 4, (2011)

7. A. Jamrozik, J. Mech. Sci. Techn. 29, 5 (2015)

8. A. Jamrozik, W. Tutak, B. Pol. Acad. Sci.-Tech. Sci. 62, 4 (2014)

9. A. Atmanli, E. Ileri, B. Yuksel, N. Yilmaz, Appl. Energ. 145, 7 (2015)

10. W. Tutak, K. Lukács, S. Szwaja, A. Bereczky, Fuel 154, 10 (2015)

11. W. Tutak W, Energ. Convers. Manage. 86, 9 (2014)

12. A. Atmanli, Fuel 172, 8 (2016)

13. B.R. Kumar, S. Saravanan, Renew Sust. Energ. Rev. 60, 11 (2016)

14. M. Mikulski, K. Duda, S. Wierzbicki, Fuel 164, 13 (2016)

15. M. Dębowski, M. Zieliński, A. Grala, M. Dudek, Renew. Sust. Energ. Rev. 27, 8 (2013)

16. W. Tutak, A. Jamrozik, M, Pyrc, M. Sobiepański, Fuel Process Technol. 149, 9 (2016)

17. S. Kumar, J.H. Cho, J. Park, I. Moon, Renew. Sust. Energ. Rev. 22, 26 (2013)

18. X. Zhen, Y Wang, Renew. Sust. Energ. Rev. 52, 16 (2015)

19. B. Rajesh Kumar, S. Saravanan, Renew. Sust. Energ. Rev. 60, 31 (2016)

20. C. Mishra, P. Mishra, B. Kar, N. Katiyar, SAE Tech. Paper 2015-26-0055, (2015)

21. I. Amr, Appl. Therm. Eng. 103, 8 (2016)

22. M. Gruca, J. Kones 11, 6 (2004)

23. W. Tutak, A. Jamrozik, Chem. Process Eng. 32, 3 (2011)

24. L. Zhu, C.S. Cheung, W.G. Zhang, Z. Huang, Fuel 90, 7 (2011) 